\title{
BMJ Open Understanding neighbourhood retail food environmental mechanisms influencing BMI in the Caribbean: a multilevel analysis from the Jamaica Health and Lifestyle Survey: a cross- sectional study
}

Colette Andrea Cunningham-Myrie (1) , ${ }^{1}$ Novie O Younger, ${ }^{2}$ Katherine P Theall, ${ }^{3}$ Lisa-Gaye Greene, ${ }^{4}$ Parris Lyew-Ayee, ${ }^{4}$ Rainford Wilks ${ }^{2}$

To cite: Cunningham-Myrie $\mathrm{CA}$, Younger NO, Theall KP, et al. Understanding neighbourhood retail food environmental mechanisms influencing BMI in the Caribbean: a multilevel analysis from the Jamaica Health and Lifestyle Survey: a cross-sectional study. BMJ Open 2020;10:e033839. doi:10.1136/ bmjopen-2019-033839

- Prepublication history and additional material for this paper are available online. To view these files, please visit the journal online (http://dx.doi. org/10.1136/bmjopen-2019033839).

Received 23 August 2019 Revised 25 May 2020 Accepted 14 July 2020

Check for updates

(c) Author(s) (or their employer(s)) 2020. Re-use permitted under CC BY-NC. No commercial re-use. See rights and permissions. Published by BMJ.

For numbered affiliations see end of article.

\section{Correspondence to}

Dr Colette Andrea CunninghamMyrie;

colette.cunninghammyrie@ uwimona.edu.jm

\section{ABSTRACT}

Objective To derive estimates of the associations between measures of the retail food environments and mean body mass index (BMI) in Jamaica, a middleincome country with increasing prevalence of obesity. Design Cross-sectional study.

Setting Data from the Jamaica Health and Lifestyle Survey 2008 (JHLS II), a nationally representative population-based survey that recruited persons at their homes over a 4-month period from all 14 parishes and 113 neighbourhoods defined as enumeration districts.

Participants A subsample of 2529 participants aged 18-74 years from the JHLS II who completed interviewer-administered surveys, provided anthropometric measurements and whose addresses were geocoded.

Primary outcome measure Mean BMI, calculated as weight divided by height squared $\left(\mathrm{kg} / \mathrm{m}^{2}\right)$.

Results There was significant clustering across neighbourhoods for mean BMI (intraclass correlation coefficients $=4.16 \%$ ). Fully adjusted models revealed higher mean $\mathrm{BMl}$ among women, with further distance away from supermarkets $\left(\beta=0.12 ; 95 \% \mathrm{Cl} 8.20 \times 10^{-3}\right.$, $0.24 ; p=0.036$ ) and the absence of supermarkets within a $1 \mathrm{~km}$ buffer zone $(\beta=1.36 ; 95 \% \mathrm{Cl} 0.20$ to 2.52; $p=0.022$ ). $A 10 \mathrm{~km}$ increase in the distance from a supermarket was associated with a $1.7 \mathrm{~kg} / \mathrm{m}^{2}$ higher mean BMI $(95 \% \mathrm{Cl} 0.03$ to $0.32 ; \mathrm{p}=0.020)$ in the middle class. No associations were detected with fast-food outlets or interaction by urbanicity.

Conclusions Higher mean BMI in Jamaicans may be partially explained by the presence of supermarkets and markets and differ by sex and social class. National efforts to curtail obesity in middle-income countries should consider interventions focused at the neighbourhood level that target the location and density of supermarkets and markets and consider sex and social class-specific factors that may be influencing the associations.
Strengths and limitations of this study

- This study is the first in a Caribbean island to demonstrate the influence of the retail food environment on body mass index (BMI) using geocoded data and multilevel modelling.

- This study provided a large sample size representative of Jamaicans 15-74 years.

- Individual geocoded addresses from a nationally representative survey were linked with specific objective geographic information system-based retail food environmental measures.

- Enumeration districts were used to define Jamaican neighbourhoods which are quite heterogeneous geographically in size, composition and context, and may not fully represent exposure to the food obesogenic environments.

- The reliability and validity of the area-level environmental variables used were not ascertained for the local context and therefore they may not be the most effective in explaining any variance in BMI.

\section{INTRODUCTION}

Obesity has been increasing in the Caribbean ${ }^{12}$ and in Jamaica is now a major public health problem. ${ }^{3}$ Over the past five decades a rapid increase in obesity has been reported with women having consistently higher rates than men. ${ }^{4-6}$ The Jamaica Health and Lifestyle Survey 2008 (JHLS II ${ }^{3}$ has documented increased prevalence over the earlier 2001 survey (JHLS I) ${ }^{7}$ in obesity as well as the comorbid chronic non-communicable disease (NCD) conditions of diabetes mellitus and hypertension. Approximately 99\% of Jamaicans consumed below the daily recommended portions of fruits and vegetables and 
$30 \%$ of obese persons preferred fried protein in their diets. $^{3}$

The presence of supermarkets/markets has been thought to indicate better access to and intake of healthier foods, given its association with higher intake of fruits and vegetables ${ }^{8}$ and inversely associated with obesity. ${ }^{9-11}$ For example, among Canadian children residing in Toronto, those who lived in close proximity to a supermarket had decreased odds of being overweight or obese. ${ }^{12}$

The presence of supermarkets has been shown to be inversely associated with neighbourhood socioeconomic status (SES) in the USA, whereby data have revealed greater poverty being associated with a decreased presence. ${ }^{13}{ }^{14}$ With regard to sex differences, research by Wang et $\mathrm{al}^{15}$ among adults aged 25-74 years in California revealed that closer proximity to a supermarket and higher neighbourhood density of small grocery stores were associated with higher body mass index (BMI) among women.

Fast-food outlets (FFO) have increased in many countries and thought to be associated with the global rise in obesity. While there is no universally accepted agreement on what the definition of fast food is, most research includes foods sold that are low cost, energy dense with high fat and/or sugar content and low nutrient content. Studies have found that frequent consumption of fast foods in areas with a high density of FFOs has been found to increase body weight ${ }^{1617}$ and a positive association of proximity to FFOs with measures of adiposity. ${ }^{18} 19$

The interaction between SES and the density of FFOs has also been investigated. In Australia, it was found that persons with poor SES (based on median weekly income) had 2.5 times exposure to FFOs than persons in the wealthiest SES category. ${ }^{20}$ Similar associations have been reported in the $\mathrm{USA}^{21}{ }^{22}$ and Great Britain. ${ }^{23}$ In Europe, eating at restaurants (which included eating at FFOs) was positively associated with BMI among men. ${ }^{24}$ On the other hand, in the USA eating at FFOs was positively associated cross-sectionally with BMI among low-income women. ${ }^{25}$

The limited body of research on environment influences on the chronic NCDs in Jamaica and the developing world, as well as the apparent lack of lifestyle changes despite health promotion programmes targeting individual-level prevention, suggests that barriers to these changes may yet be unrecognised and accounted for in the traditional modelling of risk factors. The studies on obesity previously referenced ${ }^{3467}$ have only assessed geographical variations according to the dichotomised classification of urban/rural area of residence. Within the Caribbean and Latin American regions, there are a limited number of studies assessing geographical variations in obesity or other measures of adiposity such as mean BMI, using multilevel modelling (MLM) statistical techniques and/or geographic information systems (GIS) to determine whether there are associations with the built environment in a middleincome country (MIC) or small island-developing state (SIDS) context. ${ }^{26-28}$
The aim of this study was to provide a unique and important opportunity to address these gaps in understanding the retail food environmental mechanisms influencing mean BMI in Jamaica, a small island MIC. Our objective was to derive estimates of the associations between measures of the retail food environments and mean BMI, using a combination of MLM and GIS-based methods for contextualising the national survey data and calculating objective community exposures.

We hypothesised that: (A) there was variability in the mean BMI across Jamaican neighbourhoods, (B) the pathway between greater presence/closer proximity to supermarkets/markets, and lower mean BMI would be stronger for those of higher SES, (C) the pathway between greater presence/closer proximity to FFOs and greater mean BMI would be stronger for those of low SES and residing in urban areas, and (D) there would be sex differences in these associations.

\section{MATERIALS AND METHODS Study design and sample}

The JHLS II was a cross-sectional, intervieweradministered, island-wide survey over a 4 -month period between 2007 and 2008. The sample of 2848 participants aged 15-74years represented approximately $70 \%$ of the predominantly (94\%) Black Jamaican population. ${ }^{3}$ A stratified random sample of clusters known as enumeration districts (ED) was selected using a probability proportionate to the size of population of the parishes in the island in order to yield a nationally representative sample. Trained interviewers administered a structured questionnaire on diseases and lifestyle behaviours and performed anthropometry. Further details on the sampling technique are provided elsewhere. ${ }^{3}$

A total of 2529 (or $89 \%$ of) participants from the JHLS II data set were geocoded out of the original 2848 participants. Kreft and De Leeuw ${ }^{29}$ suggest a '30/30 rule' so that researchers should strive for a sample of at least 30 groups with 30 individuals per group. For this study, each of the 101 EDs (sampling units) had an average of 28 individuals, providing sufficient power for the proposed secondary multilevel analyses. Furthermore, we also calculated power to detect a difference in BMI from 2 to 10 units based on differences in food environment exposure, at alpha $=0.05$ and power of $80 \%$, with a design effect employed ranging from an intraclass correlation coefficient (ICC) of $2 \%$ to $10 \%$ and in all scenarios our sample and number of groups were sufficient to detect this difference in BMI.

\section{Patient and public involvement}

No patients were involved in the study. The study participants were community residents and were not involved in the design, recruitment or the conduct of the study. The study findings will be disseminated to the Ministry of Health, Jamaica and general public, including the study participants. 


\section{Measures}

Individual-level measures

The primary outcome was mean BMI, calculated as weight divided by height squared $\left(\mathrm{kg} / \mathrm{m}^{2}\right)$. Weight was measured using calibrated electronic scales (Tanita models HD 314 or 2204 ) to $0.1 \mathrm{~kg}$ precision and height measured using a portable stadiometer (Seca) to $0.1 \mathrm{~cm}$ precision.

Additional covariates included age, sex, educational attainment, occupation, urbanicity and perceived community safety, and were examined as potential confounders; sex and urbanicity were also examined as effect modifiers, based on a priori theory. Named jobs were first categorised using the Jamaica Standardised Occupational Classification codes for $1991^{30}$ which comprised 16 categories. These were collapsed into four groups: (A) highly skilled/professional (legislators, senior officials and managers, professionals/technicians and associate professionals, clerks, service workers and shop and market sales workers), (B) skilled (skilled agricultural and fishery workers, craft and related trade workers, plant and machine operators and assemblers), (C) unskilled (elementary occupations), and (D) unemployed/other (armed forces, retired, unemployed, housewife, selfemployed, student and unclassified).

Perception of community safety was determined by asking each participant how safe he or she felt to walk in the community.

\section{Household-level measures}

The number of possessions owned (including but not exclusive to owning a radio, telephone, refrigerator, television, computer or car ownership) was used as a proxy for $\mathrm{SES}^{3}$ and classification based on the following tertiles: first tertile $=$ lower class $=\leq 6$ items, second tertile $=$ middle class $=7-9$ items, third tertile $=$ upper class $=10-16$ items. The tertile categorisation was based on the distribution of ownership of these items. SES, using this definition, was examined as a potential confounder or effect modifier, based on a priori theory.

\section{Environment-level measures}

Each observation was linked, through a geocoded residential address, to neighbourhood-level proximity and density measures for supermarkets, markets and FFOs. Neighbourhood was defined as the ED. The final choices of environment-level measures for investigation were based on a combination of previously derived GIS-based measures, ${ }^{31} 32$ documented associations seen with the outcome of interest ${ }^{3133}$ and data availability.

The locations of supermarkets/markets (figure 1A) and FFOs (figure 1B) were identified from Mona GeoInformatics Institute's (MonaGIS) proprietary JAMNAV database, and were collected in 2009. The proximities and densities of supermarkets/markets and FFOs were estimated using application of Spatial Analyst tool in ArcGIS to data from MonaGIS proprietary JAMNAV database. Proximity of supermarkets and markets, combined to represent good sources of fresh fruits and vegetables,
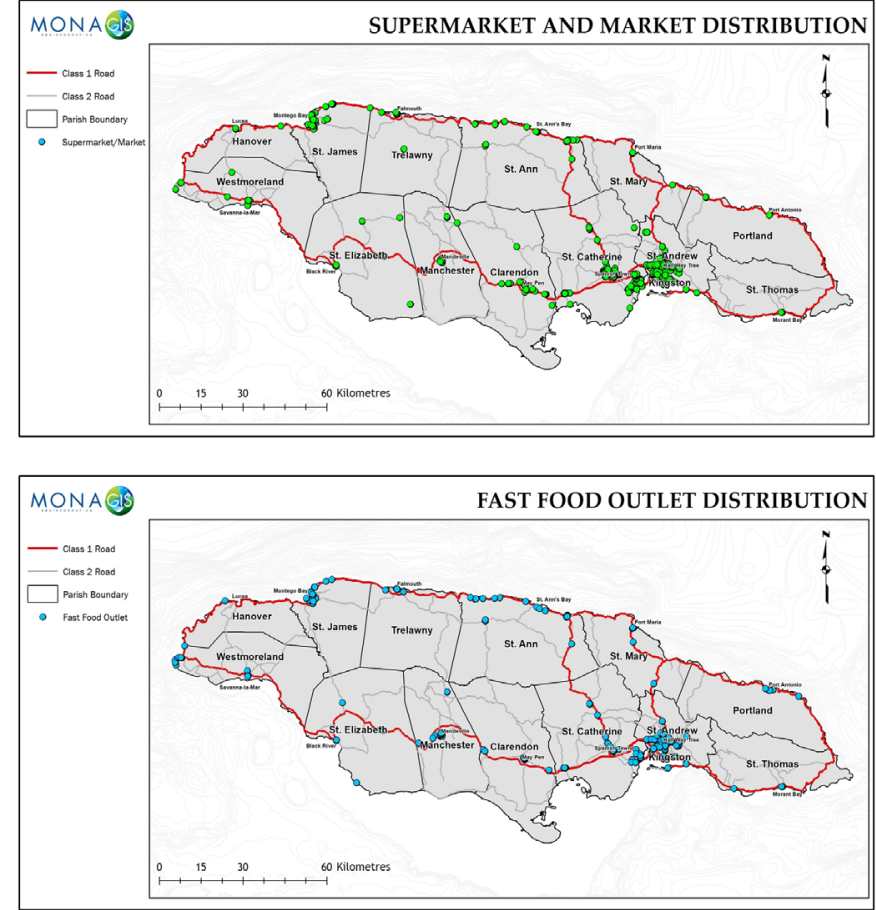

Figure 1 Spatial distribution of supermarkets/markets (A) and fast-food outlets in Jamaica (B).

was determined as the straight-line distance $(\mathrm{km})$ from each geocoded address to the closest supermarket or market. Two density variables were created. The first was supermarkets/markets per $\mathrm{km}^{2}$, and the second density variable, the number of supermarkets/markets per 1000 persons in the corresponding ED according to the 2011 census from the Statistical Institute of Jamaica. ${ }^{34}$ Buffer zones were set at $1 \mathrm{~km}$ to reflect a short walking distance that could be completed in about $10-15$ min. ${ }^{35}$

FFOs were defined as places where high-caloric food could be obtained relatively quickly and excluded traditional cook shops, snack shops and sit-down restaurants. Proximity and density measures were created in a similar way as done for supermarkets/markets.

The above-mentioned retail food environments excluded informal food spaces (eg, street vendors).

\section{Zero-inflated variables}

The absence of the environmental-level measure based on the participant's geocoded address was indicated by a large proportion of zero values for most density measures as shown in the online supplementary table. New indicator variables (dummy variables) were subsequently created and the specific dummy variable included in regression models alongside the original quantitative forms of the respective retail food environmental-level explanatory variable. These dummy variables are also referenced as the zero-inflated form of the density measures.

\section{Missing variables}

Addresses for $11 \%$ of the JHLS II study participants could not be geocoded and contributed to missing data in subsequent analyses. The age/sex population of the data 
set used for this JHLS II secondary analysis subsample was compared with that for the non-geocoded data and no key deviations were observed.

Geocoded and non-geocoded (missing) participants were compared with respect to age, sex, SES categories and the key outcome variable of mean BMI, using mixed effects models, regression models accounting for survey design and regression models that ignored survey design. No associations were detected between the geocoded status (present or missing) and these other variables. This data analysis was done only on geocoded data, on the assumption that these participants were representative of the target population.

\section{Statistical analyses}

A complex database was created that combined individuallevel JHLS II data with contextual environment-level data.

Descriptive data analysis estimated sex-specific and total survey-weighted means, proportions and 95\% CIs for the outcome, explanatory and confounding variables as well as age-adjusted mean BMI and prevalence of poor fruit and vegetable intake, a key cardiovascular disease (CVD) risk factor. Age adjustment used direct standardisation across the strata identified as 10 years age band with weights being survey-weighted population proportions of the respective 10 years age group, as estimated using the JHLS II data.

The adjusted Wald test and the Pearson's $\chi^{2}$ test corrected for survey design were used to determine whether, respectively, the age-adjusted and unadjusted estimates differed with respect to sex.

ICCs from hierarchical models quantified the proportion of variation in mean BMI potentially explainable at the ED level.

To determine and account for the effect of clustering at the neighbourhood level, subsequent analyses used multilevel models based on EDs nested within parish and examined the stratum-specific estimates of the effect of the environment variables on mean BMI with and without adjustment for covariates. Strata were defined using the urbanicity, sex and SES variables and stratumspecific multilevel models estimated if terms for interaction between the environment and strata variables were statistically significant. The Akaike information criterion statistic was used to determine the final best models. Collinearity assessed using Goodman and Kruskal's gamma coefficient $\gamma^{36}$ was the basis for selection of model covariates. To assess the chance of false positive errors, $p$ values from these models were compared with the Bonferroni corrected significance level.

All analyses were conducted using STATA V.12 and V.14 (StataCorp, College Station, Texas).

\section{RESULTS}

\section{Sample characteristics}

The weighted total and sex-specific summary statistics are shown in table 1 . Women had higher mean BMI than men and higher proportions in the highly skilled/professional, unskilled and unemployed categories and in both first and second SES tertiles based on number of possessions owned $(\mathrm{p}<0.001)$. However, a greater proportion of men perceived their communities as unsafe (males $=86.29 \%$; $95 \%$ CI $82.64 \%$ to $89.94 \%$ vs females $=80.38 \%$; $95 \%$ CI $75.63 \%$ to $85.13 \%$; $\mathrm{p}=0.012$ ). There were no sex differences in urbanicity nor among those who had not completed high school.

There was clustering in mean BMI across neighbourhoods in Jamaica, with an ICC of $4.16 \%$, the proportion of the variance in mean BMI that can be accounted for by the neighbourhood level. ${ }^{29}{ }^{37}$ No associations were found between the retail food environment variables and mean BMI in unadjusted regression models. There was also no effect modification by urbanicity.

\section{Sex-specific regression models}

There was interaction between sex and the following variables in their relationship with mean BMI: supermarket proximity $(\mathrm{p}=0.023)$, absence of supermarkets within a $1 \mathrm{~km}$ buffer zone $(\mathrm{p}=0.008)$ and FFO proximity $(\mathrm{p}=0.031)$. Figure 2 reveals that for women, in fully adjusted models, a $10 \mathrm{~km}$ increase in distance from supermarkets (or further proximity) was associated with a $1.20 \mathrm{~kg} / \mathrm{m}^{2}$ higher mean BMI $\left(95 \%\right.$ CI $\left.8.20 \times 10^{-3}, 0.24 ; \mathrm{p}=0.036\right)$; the absence of supermarkets within a $1 \mathrm{~km}$ buffer zone was associated with a $1.36 \mathrm{~kg} / \mathrm{m}^{2}$ higher mean BMI (95\% CI 0.20 to 2.52; $\mathrm{p}=0.022$ ). Proximity to FFOs was not associated with mean BMI in any sex.

\section{SES tertile-specific regression models}

There was interaction between SES of a participant and a few retail food environment variables in their relationship with mean BMI. These included supermarket proximity $(\mathrm{p}=0.015)$, absence of supermarkets $/ 1000$ people/ED $(\mathrm{p}=0.033)$ and FFO proximity $(\mathrm{p}=0.045)$. Figure 3 reveals that a kilometre increase in the distance from a supermarket was consistently associated with higher mean BMI for all models for persons within the middle class, with a $0.17 \mathrm{~kg} / \mathrm{m}^{2}$ higher mean BMI $(95 \%$ CI 0.03 to 0.32 ; $\mathrm{p}=0.020$ ) in the final model. Among persons in the upper class, the absence of supermarkets/ 1000 people/ED was associated with a $2.00 \mathrm{~kg} / \mathrm{m}^{2}$ higher mean BMI $(95 \%$ CI 0.08 to 3.92 ; $\mathrm{p}=0.041$ ) only in age-adjusted models. Proximity to FFOs was not associated with mean BMI in any of the SES classes

\section{DISCUSSION}

This study is the first to examine the impact of the retail food environment on obesity-related outcomes in a small Caribbean island. While we observed no significant associations between the retail food environment variables and mean BMI in unadjusted regression models, results revealed significant sex differences in the impact of the food environment, particularly for supermarkets. The further distance away from supermarkets and markets, 
Table 1 Total and sex-specific weighted sample characteristics (95\% Cl) for Jamaicans (JHLS II, 2008)

\begin{tabular}{|c|c|c|c|c|}
\hline Variable & Men $(n=796)$ & Women $(n=1731)$ & Total $(n=2527)$ & p value \\
\hline \multicolumn{5}{|l|}{ Individual-level measures } \\
\hline Mean age, years (\%) & 37.00 (36.33 to 37.13$)$ & 36.73 (36.64 to 37.36$)$ & 36.87 (36.54 to 37.20$)$ & 0.158 \\
\hline$<$ High school education (\%) & 31.75 (27.17 to 36.33$)$ & 29.13 (25.69 to 32.56$)$ & 30.43 (26.96 to 33.90$)$ & 0.208 \\
\hline Occupation (\%) & & & & $<0.0001$ \\
\hline Skilled & 40.33 (35.19 to 45.48$)$ & 8.21 (6.19 to 10.23$)$ & 24.23 (21.29 to 27.16$)$ & \\
\hline Unskilled & 9.75 (6.66 to 12.84$)$ & 18.13 (15.20 to 21.06$)$ & 13.95 (11.33 to 16.57$)$ & \\
\hline Unemployed/other & 11.05 (8.22 to 13.88$)$ & 21.11 (18.17 to 24.06$)$ & $16.10(14.12$ to 18.07$)$ & \\
\hline Possessions owned (\%) & & & & $<0.001$ \\
\hline Lower class $\leq 6$ items & 34.09 (29.03 to 39.14$)$ & 41.51 (37.45 to 45.57$)$ & 37.82 (33.96 to 41.68$)$ & \\
\hline Perception of unsafe community (\%) & 86.29 (82.64 to 89.94) & 80.38 (75.63 to 85.13$)$ & 83.32 (79.77 to 86.86$)$ & 0.012 \\
\hline Mean BMI $\left(\mathrm{kg} / \mathrm{m}^{2}\right)$ & 24.83 (24.28 to 25.38$)$ & 28.40 (27.90 to 28.89$)$ & $26.64(26.21$ to 27.07$)$ & $<0.001$ \\
\hline \multicolumn{5}{|l|}{$\begin{array}{l}\text { Neighbourhood-level measures }{ }^{\star}(\text { mean } \\
(95 \% \mathrm{Cl}))\end{array}$} \\
\hline Supermarket† proximity (km) & 3.61 (2.69 to 4.54$)$ & 3.64 (2.78 to 4.49$)$ & 3.63 (2.77 to 4.48$)$ & 0.978 \\
\hline Supermarkets $\uparrow / \mathrm{km}^{2}$ & $1.60(0.84$ to 2.36$)$ & 1.57 (0.96 to 2.19$)$ & 1.59 (0.91 to 2.26$)$ & 0.895 \\
\hline Supermarkets $\uparrow / 1000$ people/ED & $0.65(0.27$ to 1.04$)$ & 0.63 (0.20 to 1.07$)$ & 0.64 (0.26 to 1.03$)$ & 0.922 \\
\hline FFO proximity (km) & 4.56 (3.54 to 5.58$)$ & 4.68 (3.60 to 5.76$)$ & 4.62 (3.62 to 5.62 ) & 0.747 \\
\hline $\mathrm{FFO} / \mathrm{km}^{2}$ & $0.57(0.33$ to 0.81$)$ & $0.52(0.32$ to 0.72$)$ & 0.55 (0.33 to 0.76$)$ & 0.266 \\
\hline
\end{tabular}

$p$ values for difference between means (men vs women).

${ }^{*}$ Age adjusted.

†Includes supermarkets and markets.

BMI, body mass index; ED, enumeration district; FFO, fast-food outlet; JHLS II, Jamaica Health and Lifestyle Survey II.

and their absence within a $1 \mathrm{~km}$ buffer zone from residences, were associated with higher mean BMI in women; and further proximity to supermarkets associated with higher mean BMI for the middle class. There was no association with proximity to or density of FFOs, nor urbanrural differences.

We also observed clustering of BMI at the community level, with approximately $4.0 \%$ of the variance in mean BMI potentially explainable by environmental influences outside of the individual or at the neighbourhood level. This is similar to those reported by Harrington and Elliott ${ }^{38}$ in a Canadian sample and by Masood and Reidpath ${ }^{39}$ for many of the countries that participated in the 2003 World Health Survey. It is also similar to ICC by neighbourhood seen for obesity-related outcomes among adolescents in the USA as part of the National Health and Nutrition Examination Survey (NHANES) ${ }^{40}$

Our study findings corroborate previous research conducted in developed countries that indicate closer proximity to supermarkets/markets ${ }^{12} 1920$ and increased density of supermarkets/markets ${ }^{9-11} 164142$ are associated with less obesity-related outcomes in adults and children.
Of note however, Wang and colleagues found higher neighbourhood density of small grocery stores associated with higher BMI among a sample of US women, ${ }^{15}$ while our study found higher BMI for women being associated with further distance from supermarkets/markets (inclusive of small grocery stores). There are potential explanations for this sex-specific difference as some studies have found that residential environments have a greater effect on women's health. ${ }^{43}$ For example, women as primary food providers may depend more on neighbourhood sources for food than men do, which may in turn have an effect on their health outcomes, such as BMI. However, the influence of gender-specific roles in the provision of food supplies for families was not the focus of our study and so additional studies would be needed to better understand the differences observed. Although the geographic variables are somewhat dissimilar (a density vs proximity measure), the difference in direction of the associations raises the question as to whether presence of grocery stores, supermarkets and markets across different geographical contexts, including small island states like Jamaica, represents the same degree of accessibility, 


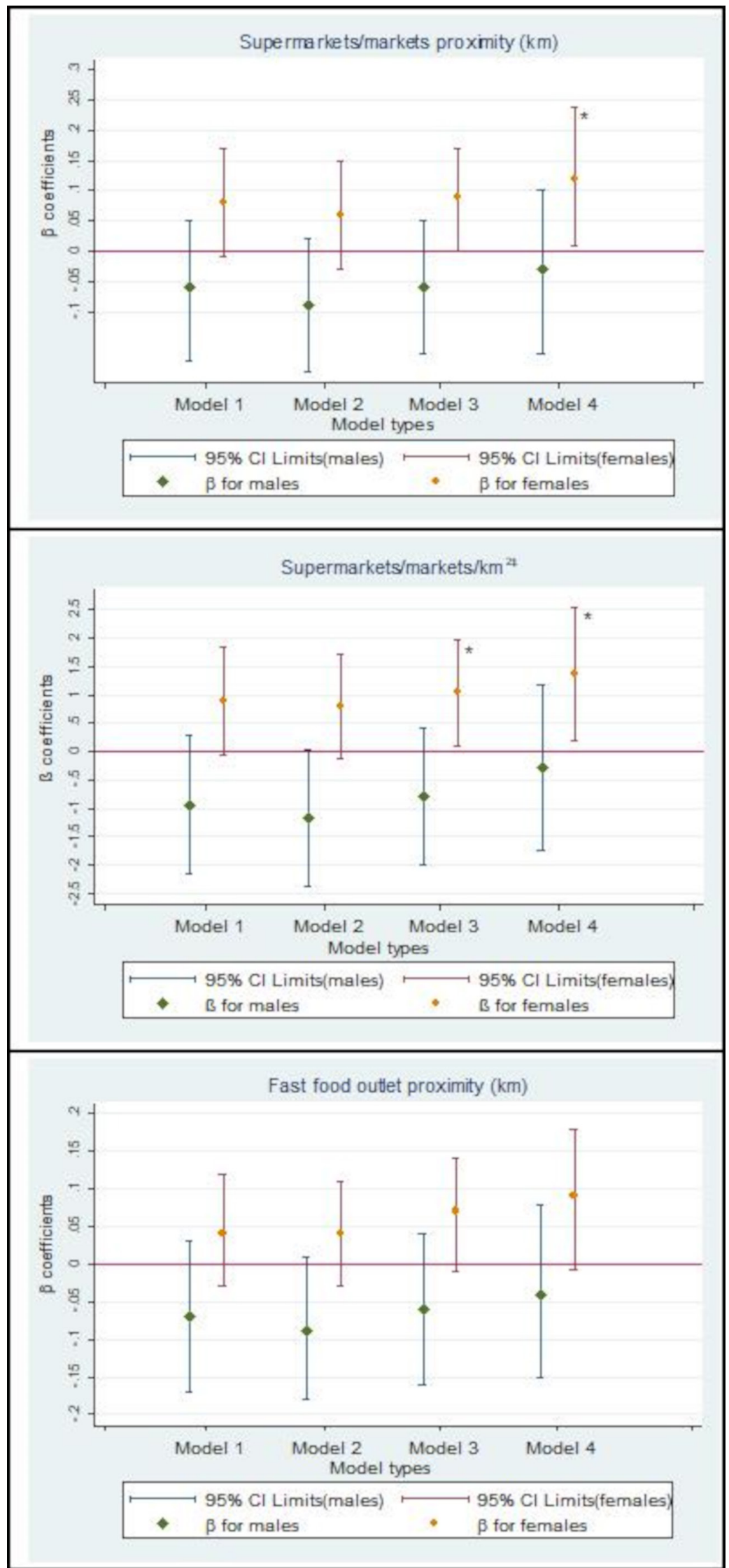

Figure 2 Sex-specific unadjusted and adjusted $\beta$ coefficients for the association of retail food environments with mean body mass index. 'Dummy variable for zero-inflated predictor. Model 1-unadjusted. Model 2-age adjusted. Model 3-adjusted for age and number of possessions. Model 4-adjusted for age, number of possessions, urban, occupation, education, perception of unsafe community. ${ }^{*} \mathrm{p}<0.05$. 


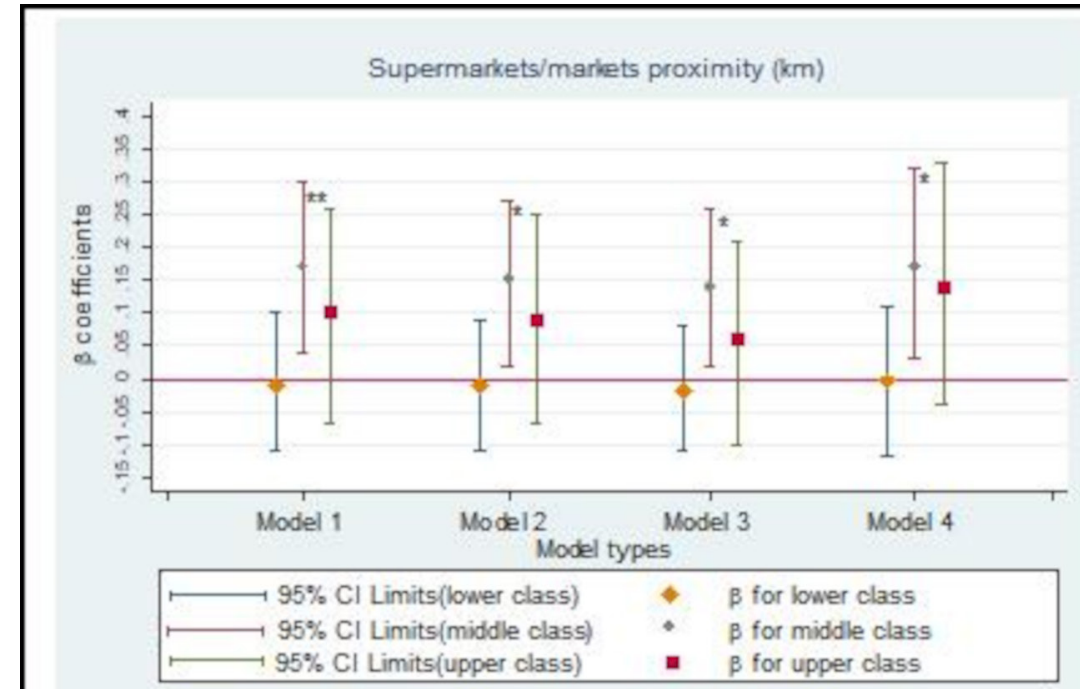

Supermarkets/markets/ 1000 persons/ED

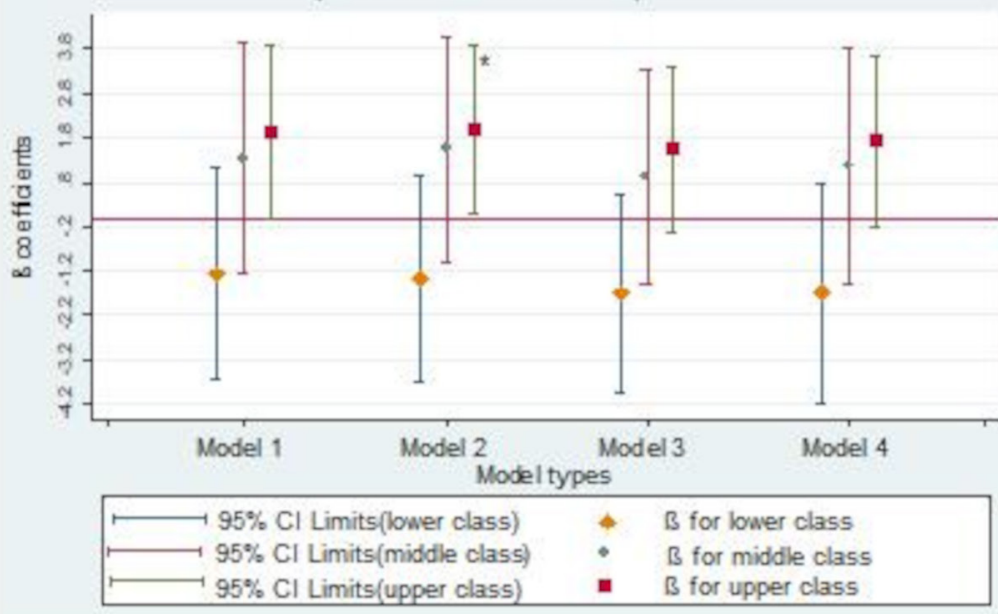

Fast food outlet proximity(km)

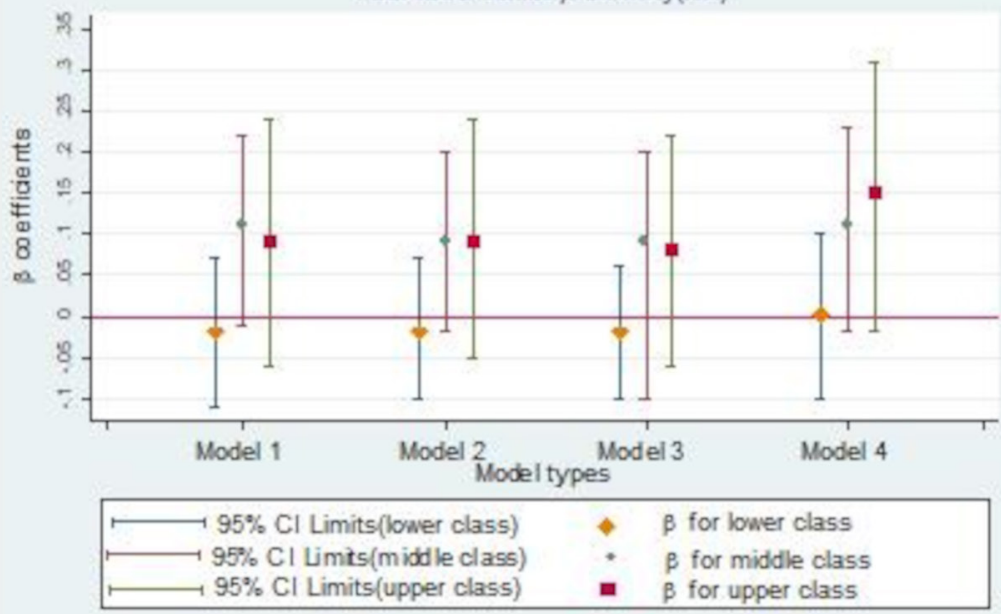

Figure 3 Socioeconomic status (SES)-specific unadjusted and adjusted $\beta$ coefficients for the association of retail food environments with mean body mass index. :Dummy variable for zero-inflated predictor. Model 1-unadjusted. Model 2-age adjusted. Model 3-adjusted for age and sex. Model 4-adjusted for age, sex, urban, occupation, education, perception of unsafe community. ${ }^{*} \mathrm{p}<0.05 ;{ }^{* *} \mathrm{p}<0.01$. ED, enumeration district. 
availability and ultimate consumption of healthy foods. For example, we found no urban-rural differences as hypothesised, perhaps due to physical activity levels (PAL), diet or some other unknown confounder masking the association. For example, it is quite possible that the presence or absence of supplementary food sources, used in rural communities and not captured in the environmental-level variables used in our study, for example, small produce plots or seasonal vegetables/fruits that supplement diets, may have played a role in the lack of urban-rural differences seen.

Living a greater distance away from supermarkets/ markets was positively associated with mean BMI in the middle class in our study, however many other studies found this association in the lower class. ${ }^{44}$ We are unclear as to the reasons for the association observed among the middle-class participants. We surmise this could possibly be due to the influence of shopping preferences in terms of location. For example, a study conducted in lowincome neighbourhoods in Philadelphia, USA, found that many residents did most of their shopping outside of the neighbourhood. ${ }^{45}$ Other possible influences could be cost, types of food purchased or lower PALs in this group, the latter perhaps being influenced by car ownership and/or greater use of motorised transport. Inagami et $a t^{46}$ found in a study conducted in the Los Angeles area of California, USA, that BMI was higher (A) where persons frequented grocery stores located in more disadvantaged neighbourhoods, which usually have higher availability of relatively inexpensive, energy-dense foods and (B) among those who owned cars and travelled farther to their grocery stores. However, other studies reveal inconsistencies, with mixed findings across various neighbourhood food retail contexts which may be due to the heterogeneity in defining neighbourhoods using $\mathrm{SES}^{47} 48$ and methodological limitations in measuring the interrelatedness of neighbourhood residence, determinants of purchasing choices within and outside of the residential neighbourhood and issues such as dietary preferences. ${ }^{49}$ In our study, PAL, motorised transport and diet were not adjusted for in the regression models. These omissions may have suppressed associations.

It is also unclear why associations between FFO proximity and mean BMI were neither seen in the sex-specific nor SES-specific models. This may be an indication that demonstration of associations may depend on which obesogenic retail food environment variable or outcome measure of adiposity is chosen for the regression models. For example, Menke et al, ${ }^{50}$ in analysing the third US NHANES conducted, found that WC maintained a stronger association with CVD risk factors than the other measures of adiposity. Further work is needed on assessing the quality and utility of the measures used in this study as well as the development of new ones for the Jamaican and developing world context.

The major strength of this study is that it represents pioneering work in a SIDS and MIC context. We linked individually geocoded addresses from a nationally representative survey, with specific objective GIS-based retail food environment measures, and provided empirical evidence using MLM to explore the association between objective neighbourhood-level retail food environment measures and BMI. Additionally, the sample characteristics that differed significantly with sex were also included as covariates in the final models in order to minimise overestimation or underestimation of the true strength of the associations detected between the neighbourhood food retail environment measures and BMI.

Despite strengths, there are limitations that deserve mention, including the inability to make causal inferences given the cross-sectional design of the JHLS II and our definition of neighbourhood. Using EDs to represent a Jamaican neighbourhood could be deemed inadequate as they (1) are quite heterogeneous geographically in size, composition and context, and (2) may not fully represent exposure to the obesogenic environments being investigated. Additionally, although the outcome was objectively assessed, the risk factors included self-reported data on a single individual representing a household, which may introduce information bias. Furthermore, there was temporal mismatch of the data collected from individual JHLS II participants with that for the retail food environment-level variables, most of which were collected by MonaGIS in and after the year 2009, subsequent to the end of data collection for the JHLS II in 2008. This may have biased the results as individual exposures may have varied after the survey period, although food consumption behaviours are believed to be relatively stable over time. Lastly, the reliability and validity of the area-level environmental variables were untested locally and therefore uncertainty remains as to whether they were most effective in explaining any variance in the obesity-related outcomes. For example, a study conducted in a low-income neighbourhood in Spain found a mismatch between GISbased measures of the food environment and resident's perceptions of the environment. ${ }^{51}$ Another challenge faced in Jamaica with accurately characterising the neighbourhood retail food environment relates to the presence and patronage of the foods provided by many itinerant vendors which are often energy-dense foods. The use of mixed methods approaches in future research within SIDS similar to Jamaica may improve understanding on the associations with observed health-related behaviours such as food purchases (cost and locations) and dietary choices with BMI.

In conclusion, we found that further distance away from supermarkets and markets and their absence within a $1 \mathrm{~km}$ buffer zone from residences were associated with higher mean BMI, with important sex and social class differences. There has been an increase in the prevalence of obesity in Jamaica ${ }^{3}$ despite the implementation of policies and programmes to ameliorate its impact on the continuum towards NCDs. ${ }^{52}$ Higher mean BMI in Jamaicans may be partially explained by the presence of supermarkets and markets and differ by sex and social class. National efforts to curtail obesity in SIDS, like Jamaica, 
should consider the inclusion of interventions and future studies focused at the neighbourhood level that target the location and density of supermarkets and markets and those that consider sex and social class-specific factors that may be influencing the associations.

\section{Author affiliations}

${ }^{1}$ Department of Community Health and Psychiatry, University of the West Indies,

Mona, Jamaica

${ }^{2}$ Caribbean Institute for Health Research, University of the West Indies, Mona, Jamaica

${ }^{3}$ Global Community Health and Behavioral Sciences, Tulane University, New Orleans, Louisiana, USA

${ }^{4}$ Mona GeoInformatics Institute, University of the West Indies, Mona, Jamaica

Contributors CACM and KPT conceived the study. LGG and PLA geocoded the data. CACM, NOY and KPT analysed and interpreted the data. RW supervised the research. CACM wrote the manuscript. PLA, KPT and RW edited the manuscript. All authors provided critical intellectual contributions and read and approved the final manuscript.

Funding This secondary analysis research received no specific grant from any funding agency in the public, commercial or not-for-profit sectors.

Map disclaimer The depiction of boundaries on this map does not imply the expression of any opinion whatsoever on the part of BMJ (or any member of its group) concerning the legal status of any country, territory, jurisdiction or area or of its authorities. This map is provided without any warranty of any kind, either express or implied.

Competing interests None declared.

Patient and public involvement Patients and/or the public were not involved in the design, or conduct, or reporting, or dissemination plans of this research.

Patient consent for publication Not required.

Ethics approval The University of the West Indies/University Hospital of the West Indies Ethics Research Committee (ECP 169, 14/15).

Provenance and peer review Not commissioned; externally peer reviewed.

Data availability statement All data relevant to the study are included in the article or uploaded as supplementary information. No additional data are available.

Open access This is an open access article distributed in accordance with the Creative Commons Attribution Non Commercial (CC BY-NC 4.0) license, which permits others to distribute, remix, adapt, build upon this work non-commercially, and license their derivative works on different terms, provided the original work is properly cited, appropriate credit is given, any changes made indicated, and the use is non-commercial. See: http://creativecommons.org/licenses/by-nc/4.0/.

ORCID iD

Colette Andrea Cunningham-Myrie http://orcid.org/0000-0001-8101-4073

\section{REFERENCES}

1 Caribbean Commission on Health and Development. Report of the Caribbean Commission on health and development PGs 37-42: Ian Randle publishers, 2006. Available: http://www.who.int/macrohealth/ action/PAHO_Report.pdf?ua=1 [Accessed 28 Nov 2014].

2 Henry FJ. Obesity prevention: the key to non-communicable disease control. West Indian Med J 2011;60:446-51.

3 Wilks R, Younger N, Tulloch-Reid M, et al. Jamaica Health and Lifestyle Survey 2007-8, 2008. Available: http://www.mona.uwi.edu/ reports/health/jhlsii_final_may09.pdf [Accessed $1 \mathrm{Feb}$ 2015].

4 Ashcroft MT, Ling J, Lovell HG, et al. Heights and weights of adults in rural and urban areas of Jamaica. Journal of Epidemiology \& Community Health 1966;20:22-6.

5 Rotimi CN, Cooper RS, Ataman SL, et al. Distribution of anthropometric variables and the prevalence of obesity in populations of West African origin: the International collaborative study on hypertension in blacks (ICSHIB). Obes Res 1995;3 Suppl 2:95s-105.

6 Wilks R, Rotimi C, Bennett F, et al. Diabetes in the Caribbean: results of a population survey from Spanish Town, Jamaica. Diabet Med 1999;16:875-83.
7 Wilks R, Zohoori N, Ashley D, et al. The Jamaican Healthy Lifestyle Survey: Ministry of Health Jamaica 2000.

8 Morland K, Wing S, Diez Roux A. The contextual effect of the local food environment on residents' diets: the Atherosclerosis risk in Communities study. Am J Public Health 2002;92:1761-8.

9 Jilcott SB, Keyserling T, Crawford T, et al. Examining associations among obesity and per capita farmers' markets, grocery stores/ supermarkets, and supercenters in US counties. J Am Diet Assoc 2011;111:567-72.

10 Morland K, Diez Roux AV, Wing S, et al. Supermarkets, other food stores, and obesity: the Atherosclerosis risk in Communities study. Am J Prev Med 2006;30:333-9.

11 Rundle A, Neckerman KM, Freeman L, et al. Neighborhood food environment and walkability predict obesity in New York City. Environ Health Perspect 2009;117:442-7.

12 Larsen K, Cook B, Stone MR, et al. Food access and children's BMI in Toronto, Ontario: assessing how the food environment relates to overweight and obesity. Int $J$ Public Health 2015;60:69-77.

13 Bower KM, Thorpe RJ, Rohde C, et al. The intersection of neighborhood racial segregation, poverty, and urbanicity and its impact on food store availability in the United States. Prev Med 2014;58:33-9.

14 Moore LV, Diez Roux AV. Associations of neighborhood characteristics with the location and type of food stores. Am J Public Health 2006;96:325-31.

15 Wang MC, Kim S, Gonzalez AA, et al. Socioeconomic and foodrelated physical characteristics of the neighbourhood environment are associated with body mass index. J Epidemiol Community Health 2007;61:491-8.

16 Li F, Harmer P, Cardinal BJ, et al. Built environment and 1-year change in weight and waist circumference in middle-aged and older adults: Portland neighborhood environment and health study. Am J Epidemiol 2009;169:401-8.

17 Nago ES, Lachat CK, Dossa RAM, et al. Association of out-ofhome eating with anthropometric changes: a systematic review of prospective studies. Crit Rev Food Sci Nutr 2014;54:1103-16.

18 Reitzel LR, Regan SD, Nguyen N, et al. Density and proximity of fast food restaurants and body mass index among African Americans. Am J Public Health 2014;104:110-6.

19 Davis B, Carpenter C. Proximity of fast-food restaurants to schools and adolescent obesity. Am J Public Health 2009;99:505-10.

20 Reidpath DD, Burns C, Garrard J, et al. An ecological study of the relationship between social and environmental determinants of obesity. Health Place 2002;8:141-5.

21 Maddock J. The relationship between obesity and the prevalence of fast food restaurants: state-level analysis. Am J Health Promot 2004;19:137-43.

22 Lewis LB, Sloane DC, Nascimento LM, et al. African Americans' access to healthy food options in South Los Angeles restaurants. Am J Public Health 2005;95:668-73.

23 Cummins SCJ, McKay L, Maclntyre S. Mcdonald's restaurants and neighborhood deprivation in Scotland and England. Am J Prev Med 2005;29:308-10.

24 Naska A, Orfanos P, Trichopoulou A, et al. Eating out, weight and weight gain. A cross-sectional and prospective analysis in the context of the EPIC-PANACEA study. Int J Obes 2011;35:416-26.

25 Jeffery RW, French SA. Epidemic obesity in the United States: are fast foods and television viewing contributing? Am J Public Health 1998;88:277-80.

26 Cunningham-Myrie CA, Mabile E, Govia I, et al. Neighbourhood characteristics and cumulative biological risk: evidence from the Jamaica Health and Lifestyle Survey 2008: a cross-sectional study. BMJ Open 2018;8:e021952.

27 Jaime PC, Duran AC, Sarti FM, et al. Investigating environmental determinants of diet, physical activity, and overweight among adults in Sao Paulo, Brazil. J Urban Health $2011 ; ; 88: 567-81$. Jun 1.

28 Mendes LL, Nogueira H, Padez C, et al. Individual and environmental factors associated for overweight in urban population of Brazil. BMC Public Health 2013;13:988.

29 Kreft I, De Leeuw J. Introducing multilevel modeling. London: Sage, 1998.

30 The Statistical Institute of Jamaica (STATIN). Jamaica standard occupational classification. Statistical Institute of Jamaica, Kingston 1991.

31 Prince SA, Kristjansson EA, Russell K, et al. A multilevel analysis of neighbourhood built and social environments and adult self-reported physical activity and body mass index in Ottawa, Canada. Int $J$ Environ Res Public Health 2011;8:3953-78.

32 Brownson RC, Hoehner CM, Day K, et al. Measuring the built environment for physical activity: state of the science. Am J Prev Med 2009;36:S99-123. 
33 Prince SA, Kristjansson EA, Russell K, et al. Relationships between neighborhoods, physical activity, and obesity: a multilevel analysis of a large Canadian City. Obesity 2012;20:2093-100.

34 The Statistical Institute of Jamaica (STATIN). 2011 Census of Population and Housing - Jamaica. Available: http://statinja.gov.jm/ Census/PopCensus/Popcensus2011Index.aspx [Accessed $1 \mathrm{Apr}$ 2016].

35 Titheridge $\mathrm{H}$, Hall P. Changing travel to work patterns in South East England. J Transp Geogr 2006;14:60-75.

36 Goodman and Kruskal's gamma. in Wikipedia, the free encyclopedia, 2016. Available: https://en.wikipedia.org/w/index.php?title= Goodman_and_Kruskal\%27s_gamma\&oldid=722481108 [Accessed 28 May 2016].

37 Bryk AS, Raudenbush SW. Hierarchical linear models (applications and data analysis methods). 1992. New York: Sage Publications, 1992.

38 Harrington DW, Elliott SJ. Weighing the importance of neighbourhood: a multilevel exploration of the determinants of overweight and obesity. Soc Sci Med 2009;68:593-600.

39 Masood M, Reidpath DD. Intraclass correlation and design effect in BMI, physical activity and diet: a cross-sectional study of 56 countries. BMJ Open 2016;6:e008173.

40 Theall KP, Drury SS, Shirtcliff EA. Cumulative neighborhood risk of psychosocial stress and allostatic load in adolescents. Am J Epidemiol 2012;176 Suppl 7:S164-74.

41 Lamichhane AP, Puett R, Porter DE, et al. Associations of built food environment with body mass index and waist circumference among youth with diabetes. Int J Behav Nutr Phys Act 2012;9:81.

42 Burgoine T, Forouhi NG, Griffin SJ, et al. Associations between exposure to takeaway food outlets, takeaway food consumption, and body weight in Cambridgeshire, UK: population based, cross sectional study. BMJ 2014;348:g1464.

43 Stafford M, Cummins S, Macintyre S, et al. Gender differences in the associations between health and neighbourhood environment. Soc Sci Med 2005;60:1681-92.

44 Black JL, Macinko J. Neighborhoods and obesity. Nutr Rev 2008;66:2-20.

45 Hillier A, Cannuscio CC, Karpyn A, et al. How far do low-income parents travel to shop for food? empirical evidence from two urban neighborhoods. Urban Geogr 2011;32:712-29.

46 Inagami S, Cohen DA, Finch BK, et al. You are where you shop: grocery store locations, weight, and neighborhoods. Am J Prev Med 2006;31:10-17.

47 Odoms-Young A, Singleton CR, Springfield S, et al. Retail environments as a venue for obesity prevention. Curr Obes Rep 2016;5:184-91.

48 Gordon-Larsen P. Food availability/convenience and obesity. Adv Nutr 2014;5:809-17.

49 Ni Mhurchu C, Vandevijvere S, Waterlander W, Thornton LE, et al. Monitoring the availability of healthy and unhealthy foods and non-alcoholic beverages in community and consumer retail food environments globally. Obes Rev 2013;14 Suppl 1:108-19.

50 Menke A, Muntner P, Wildman RP, et al. Measures of adiposity and cardiovascular disease risk factors. Obesity 2007;15:785-95.

51 Díez J, Valiente R, Ramos C, et al. The mismatch between observational measures and residents' perspectives on the retail food environment: a mixed-methods approach in the Heart Healthy Hoods study. Public Health Nutr 2017;20:2970-9.

52 The National Health Fund Act, 2003. Available: http://www.moh.gov. jm/laws/statutes [Accessed 26 May 2010]. 